\title{
Development of zeolite for non-phosphated detergents in Japan
}

\author{
Izumi Yamane ${ }^{*}$ and Tadahisa Nakazawa ${ }^{* *}$ \\ * LION Corporation, 3-7, Honjo 1-Chome, Sumida-Ku, Tokyo 130, Japan \\ ** Mizusawa Industrial Chemicals Ltd., 4-5, Muromachi, Nihonbashi, Chuo-Ku, \\ Tokyo 103, Japan
}

\begin{abstract}
Under an increasing social demand for improving the so-called eutrophication problems in stagnant surface waters, the development of the zeolite for detergent-use was initiated according to the request of the detergent manufacturer. In a cooperative study with the zeolite supplier, the specifications of zeolite suitable to Japanese washing conditions were determined, and it was found that the acid clay method via activated silicic acid gel is suitable for the manufacturing process because of the economical viability and the quality of zeolite $4 \mathrm{~A}$ obtained, which has small uniformsized particles and high ion-exchange ability. By adding some improvements, specially prepared zeolite slurry was developed, which fulfills the requirements for the phosphate substitute builder.
\end{abstract}

The related technology required for manufacturing of non-phosphated detergent was also developed, particularly on formulation, spray-dry processing and improvement of the final product's physical properties. Thus nonphosphated powder detergents of high-zeolite formulation were successfully introduced since 1980, and owing to their excellent performance properties, the switchover from phosphated detergents to them has almost been completed by last year in Japan.

\section{INTRODUCTION}

Recently, "eutrophication problems" in closed or slowly flowing water areas have become serious in most countries of the world (ref. 1, 2). In Japan, since the beginning of 1970's, there were many reports about instances of eutrophications and appearances of red tides in the several lakes and inland-sea areas near by densely populated urban areas, and the measures to be taken for the protection of these water systems were being discussed from sociological view points. Three major nutrients of carbon, nitrogen and phosphorus were indicated as being contributors to undesirable acceleration of these eutrophications. Among these, phosphorus was recognized as the target component to be decreased since it was possible to control its sources. To reduce phosphorus amounts released to environment, there are two ways of the curtailing in the sources and the treating chemically in the sewage plants. In the western countries, the primary countermeasure to cope with eutrophication has been the latter as well as modification of other related social infrastructures.

In Japan, however, the coverage of the sewerage systems at that time was very unsatisfactory, with only $23 \%$ available to be treated, and it was difficult to expect that the situation would be improved in a short time. Under such circumstance, many discussions had been made about the responsibilities of the detergent-derived phosphorus in the total amounts of phosphorus found in surface waters. To cope with this situation, since 1975 the members of the Japan Soap and Detergent Association decided a voluntary guide line to reduce phosphate contents in the laundry detergents, step by step. In 1976, the level of the guide line was reduced from the initial level of $15 \%$ as $\mathrm{P}_{2} \mathrm{O}_{5}$ in 1975 to $12 \%$, and then to $10 \%$ in 1979 .

However, even with such steps being taken, no discernible improvement was observed in the eutrophication problems. In some of the specific areas facing serious eutrophication problems, the local government bodies began movements to enact ordinances to ban "phosphated detergents". The intensive studies were accelerated to challenge technical development of nonphosphated detergents. Since 1960's, numerous studies on phosphate substitutes had been made in the world, however it was expected that the full substitution of phosphates with the existing conventional builders and other ones in the similar lines was not feasible owing to the reasons described later. The appearance of a new builder was eagerly awaited for the development of non-phosphated detergents by all concerned. 


\section{SPECIFICATIONS REQUIRED FOR DETERGENT ZEOLITE}

\section{Substitute builders for non-phosphated detergent}

Polycondensed phosphates, represented by sodium tripolyphosphate (STPP), were the most commonly used builders, and they constituted the main ingredients together with surfactant materials in synthetic powder detergents for heavy duty laundry (hereafter these detergents will be described as "Phosphated detergents" in short, while no phosphate version of the said detergents will be described as "non-phosphated"). The phosphates have important properties to improve cleaning efficiency, by the effect of water softening through sequestration of calcium and magnesium ions and that of preventing soil re-deposition. In addition to these important builder properties, STPP has also excellent effects to improve physical properties of the powder detergents, especially free-flowing property and strength of the particles. Therefore if phosphate content is simply reduced or eliminated, the powder detergents obtained will suffer significant damages in their performance properties, and the end products of very poor commercial value will be obtained.

In studying on phosphate substitutes, a careful examination must be considered not only from view point of performance properties as well as cost, but also from that of sociological and safety problems which might be caused by their introduction.

For phosphate substitutes, many materials had been studied aggressively including citrates, polyacrylates, maleic acid derivatives, nitriro-triacetate(NTA) and other candidate products having calcium binding properties (ref. 3). As shown in Table 1, most of the selected products have some disadvantages. The keen interest was finally focused on zeolites as the remaining attractive material.

TABLE 1. An evaluation on selected substitute builders comparing with phosphate

\begin{tabular}{lcllll}
\hline & $\begin{array}{c}\text { Sodium } \\
\text { citrate }\end{array}$ & $\begin{array}{l}\text { Sodium } \\
\text { polyacrylate }\end{array}$ & $\begin{array}{c}\text { Sodium } \\
\text { polymaleate }\end{array}$ & $\begin{array}{c}\text { Na nitriro } \\
\text { triacetate }\end{array}$ & Zeolite \\
\hline $\begin{array}{l}\text { Calcium ion } \\
\text { binding amount }\end{array}$ & poor & excellent & equivalent & excellent & equivalent \\
\hline $\begin{array}{l}\text { Expected cost } \\
\text { position }\end{array}$ & weak & weak & weak & weak & $\begin{array}{c}\text { competitive } \\
\text { wstrong }\end{array}$ \\
\hline Safety/ecology & $\begin{array}{l}\text { increased } \\
\text { load on } \\
\text { COD }\end{array}$ & $\begin{array}{c}\text { poor } \\
\text { biodegrada- } \\
\text { bility }\end{array}$ & $\begin{array}{c}\text { poor } \\
\text { biodegrada- } \\
\text { bility }\end{array}$ & $\begin{array}{c}\text { not yet } \\
\text { cleared on } \\
\text { safety }\end{array}$ & harmless \\
\hline
\end{tabular}

\section{Basic properties for detergent zeolite}

The zeolite of $4 \mathrm{~A}$ type is the most suitable in various zeolites because of its largest ionexchange capacity (ref. 4). Prior to application for actual use, the basic performance properties were examined on possibilities of using it as a main builder material and on appropriate specifications, considering Japanese washing conditions and properties of the end products.

TABLE 2. Typical washing conditions in Japan, USA and Europe

\begin{tabular}{lcccc}
\hline & Japan & U S A & Europe \\
\hline Type of washing machine & $\begin{array}{c}\text { top loading } \\
\text { with a pulsator }\end{array}$ & $\begin{array}{c}\text { top loading } \\
\text { with an agitator }\end{array}$ & $\begin{array}{c}\text { front loading } \\
\text { with a tumbler }\end{array}$ \\
\hline $\begin{array}{l}\text { Volume of } \\
\text { washing water }\end{array}$ & $(\mathrm{l})$ & $30-45$ & $50-80$ & $20-25$ \\
\hline $\begin{array}{l}\text { Washing load } \\
(\mathrm{kg})\end{array}$ & $1-1.5$ & $3-4$ & $3-4$ \\
\hline $\begin{array}{l}\text { Recommenmded } \\
\text { detergent dosage }\end{array}(\mathrm{g} / \mathrm{l})$ & 1.3 & 1.5 & $8-10$ \\
\hline Water hardness $(\mathrm{CaCO}$ ppm) & 50 & 100 & 250 \\
\hline Washing temperature $(\circ \mathrm{C})$ & $10-25$ & $30-50$ & $60-90$ \\
\hline Washing time & $(\mathrm{min})$. & $5-15$ & $10-15$ & $30-40$ \\
\hline
\end{tabular}

As most of Japan belongs to so-called soft water areas with the hardnesses of up to 50-75ppm of $\mathrm{CaCO}_{3}$, we are fortunate that natural conditions provide us with good quality water for washing. On the other hand, we have a distinctive washing habit requiring very severe task for the detergents because of using short washing time cycles and cold water washings (In Table 2, typical washing conditions in Japan are summarized in comparison with the cases in the USA and Europe.). Therefore, Japanese washing conditions require two basic properties in a phosphate substitute zeolite; the ion-exchange ability is excellent even in cold water and; the exchange rate is high enough to capture hardness ions quickly. 


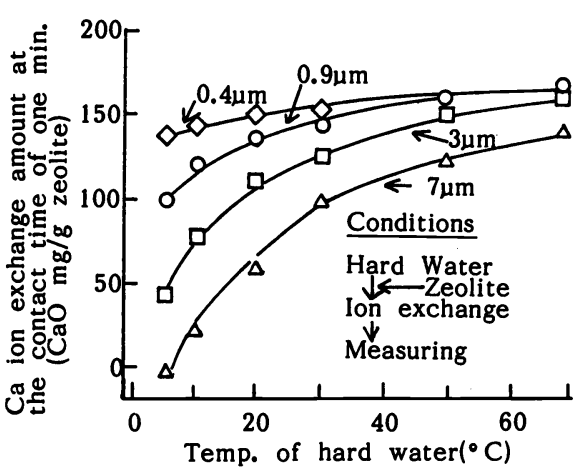

Fig. 1. Temperature vs $\mathrm{Ca}$ ion exchange amount in various particle size zeolites.

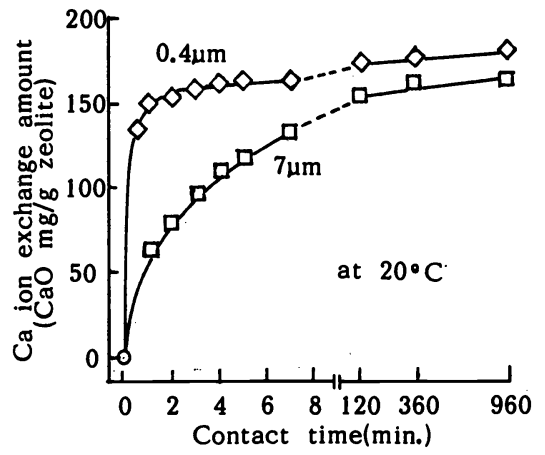

Fig. 2. Contact time vs ion exchange amount in different particle size zeolites.

The results in Fig. 1 and 2 suggest that in the same type of zeolite, its maximum ion exchanging ability at final state is almost insensitive to the particle size of zeolite, but the zeolite with a smaller particle size can capture more calcium ions within shorter time and/or at lower temperatures (ref. 5).

In heavy-duty powder detergents commonly used for laundry washing, many ingredients are formulated together with the anionic surfactants consisting of main components. In such a complex detergent system, in which zeolite is formulated as a builder, calcium ion-exchanging will occur through some routes in the water softening processes. As a solid state zeolite softens water only by a heterogeneous cation exchange process, at the initial stage a part of calcium ions will react with carriers and anionic surfactants dissolved in the system to form their calcium salts. Then their original sodium salts will be released by ion exchange of the calcium salts with the zeolite. In this process, one of the key points to get good detergency depends on how soon anionic surfactants are reproduced into original sodium salts. Therefore it is concluded that obtaining a smaller particle zeolite is very important factor, especially in Japanese washing conditions.

In applying the zeolite in the actual detergent formulation, a difficult problem appeared in the results of washing performance test. It was undesirable depositions of zeolite particles on the washed fabrics, which were observed as white, visible residues especially on the dark colored fabrics. Severe deposition was observed under the washing conditions at lower temperatures. It was worried that this trouble would be an obstacle to the development of non-phosphated detergents with zeolite. Through careful examination, it was made clear that this obstacle phenomenon was caused by the deposition of large agglomerated-particles of zeolite having diameters of above $10+\mu \mathrm{m}$. A prospect to overcome the problem was obtained by strictly controlling amounts of the large agglomerated particles in the zeolite. The cooperation of the detergent manufacturer and the zeolite supplier advanced to the next steps for the development of the manufacturing process for zeolite having the required specifications and the formulation as well as the manufacturing process for non-phosphated powder detergents, which led to the commercialization.

\section{MANUFACTURING OF DETERGENT ZEOLITE FROM ACID CLAY}

The conventional way of obtaining detergent zeolite is by the reaction of sodium silicate with sodium aluminate (ref. 6).

$$
2 \mathrm{Na}_{2} \mathrm{SiO}_{3} \text {-aq }+2 \mathrm{NaAlO}_{2} \text {-aq } \rightarrow \mathrm{Na}_{2} \mathrm{O}-\mathrm{Al}_{2} \mathrm{O}_{3}-2 \mathrm{SiO}_{2}-4.5 \mathrm{H}_{2} \mathrm{O}+4 \mathrm{NaOH}
$$

This method has been applied by Henkel KGaA (W.Germany), Degussa (W.Germany), the PQ Corporation (USA) and others for the manufacturing of detergent zeolite. In this method, a recovery system is required for sodium hydroxide yielded in large amounts as a by-product. There is another method to get the zeolite from Kaolinite via a reaction of metakaolin, obtained by calcining, with sodium hydroxide (ref. 6).

$$
\mathrm{Al}_{2} \mathrm{O}_{3}-2 \mathrm{SiO}_{2} \text { (metakaolin) }+2 \mathrm{NaOH}-\mathrm{aq} \rightarrow \mathrm{Na}_{2} \mathrm{O}-\mathrm{Al}_{2} \mathrm{O}_{3}-2 \mathrm{SiO}_{2}-4.5 \mathrm{H}_{2} \mathrm{O}
$$

Ethyl Corp. (USA) has applied this process for manufacturing of the zeolite. The important factor in this process depends on how to secure high purity kaolinite economically for the raw material.

About three decades ago Mizusawa Industrial Chemicals Ltd., had manufactured zeolite from an acid clay commercially with a unique method developed by its own technology (ref. 5). The acid clay is a mineral in montmorillonite clay which is found in nature plentifully in Japan, and it has a layer structure of hydrated silicate clay mineral as shown in Fig. 3. 


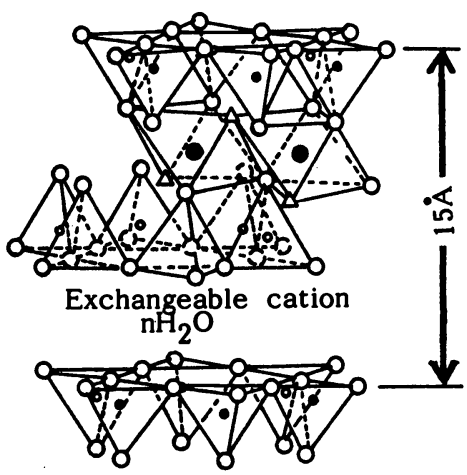

O:Oxygen

$\Delta:$ Hydroxyl group

๑:Aluminum,Iron,Magnesium

:Silicon or Aluminum

Fig. 3. Schematic crystal structure of acid clay (ref. 7).

By treating the clay with a mineral acid, the metallic elements, $\mathrm{Al}, \mathrm{Mg}, \mathrm{Ca}, \mathrm{Fe}$ and so on, are eluted, and the clay structure is destroyed into a silicic acid gel which has an activated reactivity. The gel obtained in amorphous state consists of very small, fine particles with diameters of $0.01-1 \mu \mathrm{m}$, and easily disperses into alkaline solution. By utilizing this favorable reactivity of the activated silicic acid gel, the zeolite is obtained by mixing a dispersed solution of the gel with sodium aluminum solution.

$$
2 \mathrm{SiO}_{2}+2 \mathrm{NaAlO}_{2}-\mathrm{aq} \rightarrow \mathrm{Na}_{2} \mathrm{O}-\mathrm{Al}_{2} \mathrm{O}_{3}-2 \mathrm{SiO}_{2}-4.5 \mathrm{H}_{2} \mathrm{O}
$$

Figure 4 shows a process flow diagram in this method. This method was found to have several advantages for commercialization process as follows;

Quality - It is relatively easy to obtain the zeolite with a fine, small uniform-sized particles.

Process - An acid-treatment process is required for silicic acid gel preparation, but a concentration process for execess sodium hydroxide in the filtrate is not necessary. And aluminum hydroxide is recovered from the spent acid and is economically converted to sodium aluminate.

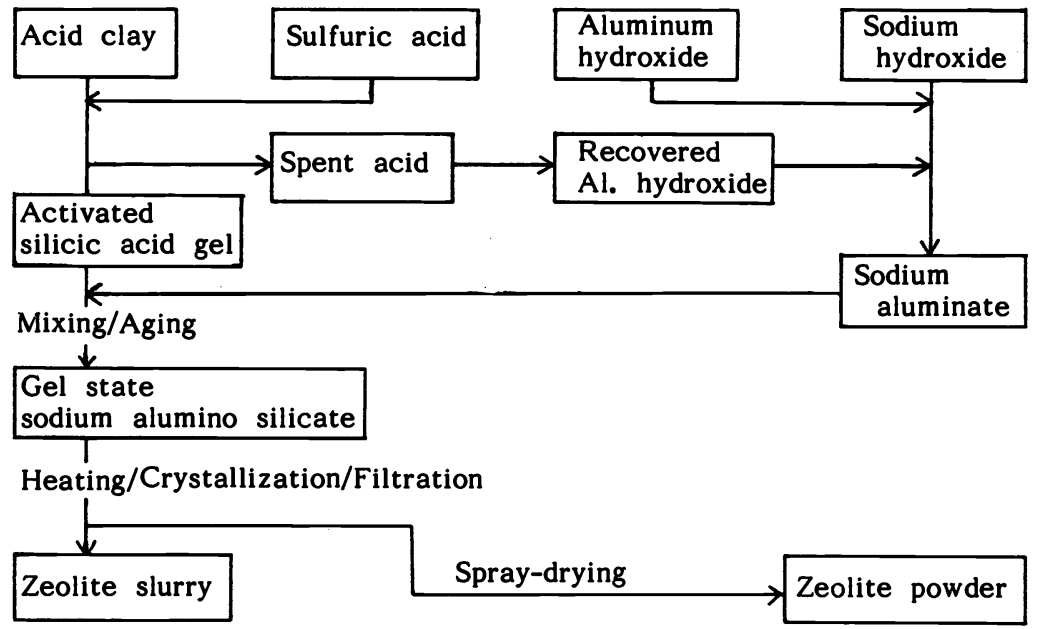

Fig. 4. A zeolite manufacturing process flow in acid clay method (ref. 5).

There are some differences in the behaviors during crystallization of zeolite $4 \mathrm{~A}$ in the three methods (ref. 8). Figure 5 shows trends of the time required for crystallization of zeolite $4 \mathrm{~A}$ in temperatures ranging from $70^{\circ}$ to $90^{\circ} \mathrm{C}$ under the conditions of the same molar ratio of $\mathrm{Na}_{2} \mathrm{O}: \mathrm{Al}_{2} \mathrm{O}_{3}: \mathrm{SiO}_{2}: \mathrm{H}_{2} \mathrm{O}=2.4: 1: 2: 96$ with sodium silicate, metakaolin and the silicic acid gel as a raw material in the three methods, respectively. As shown in the figure, the crystaflization time differs depending on the silicic sources applied, and the acid clay method showed the shortest time for zeolite crystallization.

Figure 6 shows the changes in the molar ratios of $\mathrm{SiO}_{2}$ to $\mathrm{Al}_{2} \mathrm{O}_{3}$ in (amorphous) alumino silicate gels obtained and in the ion concentrations of dissolved aluminum through a sequence of the reaction from the aging of reactants at $50 \mathrm{C}$ to the hydrothermal crystallization at $90 \circ \mathrm{C}$. In Fig. 7, the progress states of crystallizations in each method are shown in several photographs taken by scanning electron microscopy. 
There are many reports describing the yield mechanisms of zeolite crystals, and the theories will be divided roughly into two categories on the progress of crystallization;

i) Crystallizing by growth of crystal seed y.elded from a precursor in the liquid phase.

ii) Crystallizing by a solid transformation mechanism in the solid gel phase.

In the case with sodium silicate or metakaolin, the ratio of $\mathrm{SiO}_{2} / \mathrm{Al}_{2} \mathrm{O}_{3}$ in amorphous aluminum silicate gel was kept low from initial stage just after the mixing, however the crystals of zeolite scarcely appeared till sometime later after the temperature of the reaction mixture was raised to $90^{\circ} \mathrm{C}$. Contrary to this, an amorphous gel having large $\mathrm{SiO}_{2} / \mathrm{Al}_{2} \mathrm{O}_{3}$ ratio was obtained initially in the case of silicic acid gel, by mixing the acid gel, which was dispersed in alkaline solution, with sodium aluminum solution, and then the molar ratio decreased to a theoretical value of two to one in zeolite $4 \mathrm{~A}$ as the time passed. Aluminum ion concentrations in the mother liquor decreased very rapidly when the temperature went up to $90^{\circ} \mathrm{C}$, and the crystals of zeolite was almost yielded by the time when the temperature was raised to $90^{\circ} \mathrm{C}$. In this crystallization process, it seems that a part of $\mathrm{Si}-\mathrm{O}-\mathrm{Si}$ bonds in the initially yielded amorphous gel changed progressively into crystal seeds in the alkaline mother liquor via a precursor, which is not identified. Considering from these results,

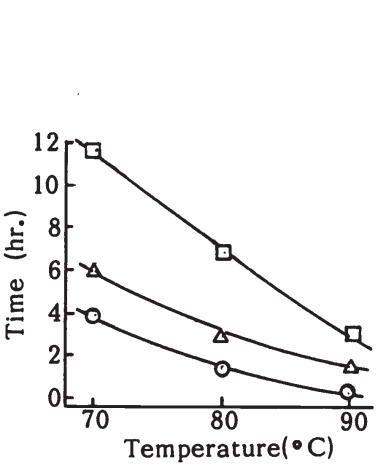

Fig. 5. Time required for zeolite crystallization.

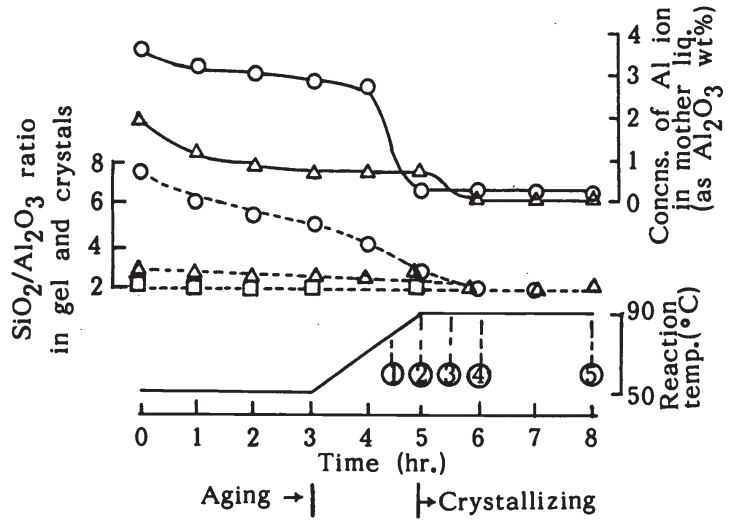

Fig. 6. Behavior in zeolite formation.
Raw material in Fig. 5 and 6:

0 : Silicic acid gel

$\Delta$ : Sodium silicate

: Metakaolin

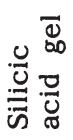

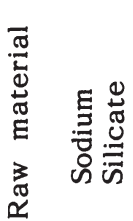

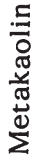

Sampling point
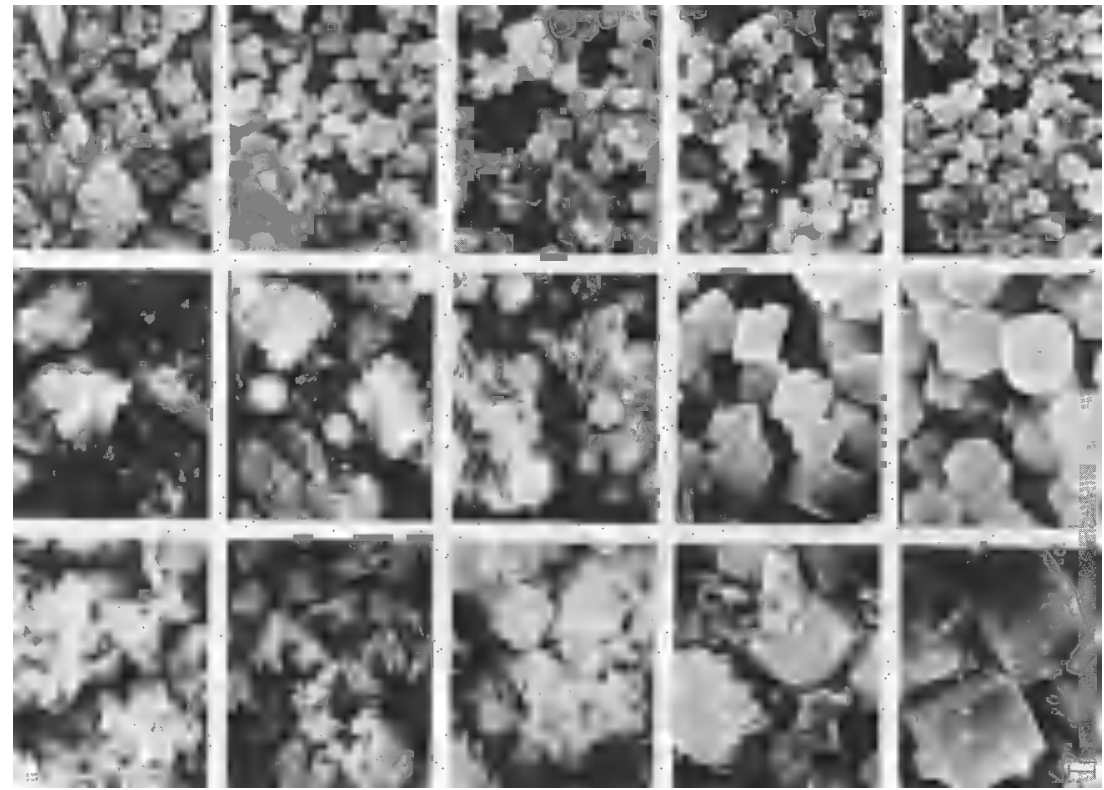

(4)

$60 \mathrm{~min}$

$20 \mathrm{~min}$.

0 min.

Crystallization time at $90^{\circ} \mathrm{C}$

(Scanning Electron Microscopy photograph, $\stackrel{0}{\longrightarrow} \mu \mathrm{m}$ )

Fig. 7. Crystallization behaviors in the period from temp.-increasing to aging. The sampling points of these specimens are noted on the temperature-time curve in Fig. 6. 
in the acid clay method, the fine particle zeolite with small diameters is obtained because the crystallization proceeds very rapidly under such conditions that numerous crystal seeds are created in the amorphous gel in the previous stage of the crystallization and the initial level of aluminum ion concentrations is relatively high.

However the zeolite particles obtained were relatively large in any case of these methods, and had a tendency to yield significant amounts of agglomelated secondary particles of large size. Therefore some modifications were needed to apply these methods for manufacturing processes for the detergent zeolite. In the acid clay method, it was found that, by a preliminary treating the silicic acid gel with diluted sodium hydroxide solution, the activity of the gel is improved significantly, and by adjusting the conditions in molar ratio of $\mathrm{Na}_{2} \mathrm{O}: \mathrm{SiO}_{2}$ to $1: 7-300$, fine zeolite particles with relatively small uniform-sizes are obtained quantitatively almost free from agglomerated secondary particles. The zeolite thereby obtained satisfied all requirements for detergent use, which were described in the above. By this improved method, the first detergent zeolite in Japan was commercialized.

The easiness in physical transportation is also an important factor in the development of the zeolite. The zeolite powder, originally used for a dry blending in the manufacturing of lowphosphated detergents to improve stickiness of the detergent particles, has been manufactured by spray drying of the zeolite slurry obtained in the zeolite plant. The zeolite powder, having specifications of bulk density of $0.4-0.6$ and average particle size of 100-300um, was milled into smaller particles consisting of essentially primary particles having bulk density of $0.2-0.3$ before being applied to dry-blending at the site of detergent manufacturing plant. In the case of non-phosphated detergents, as relatively large amounts of zeolite are formulated for phosphate substitution, the direct application of zeolite slurry is more economical for transportation, handling and storage.

Therefore the development of slurry type zeolite was required. As known, the freshly prepared zeolite slurry has a dilatancy property. The precipitated zeolite forms a hard deposition at the bottom of the slurry, which is difficult to re-disperse. So this type of zeolite slurry is not available for pumping and bulk transportation. In order to improve its handling property, the zeolite slurry having a thixotropic property was developed by adding some dispersing agents. Thus the lorry-car transportation of the slurry was realized in 1980 .

TABLE 3. Properties of zeolite slurry for detergent.

\begin{tabular}{|c|c|}
\hline Concentration & $44-45$ \\
\hline Viscosity (poise, $25^{\circ} \mathrm{C}$ ) & $2-15$ \\
\hline $\begin{array}{c}\text { Calcium ion exchange } \\
\text { amts. }(\mathrm{CaO} \mathrm{mg} / \mathrm{g})\end{array}$ & $>145$ \\
\hline Mean particle size $(\mu \mathrm{m})$ & $0.5-1.0$ \\
\hline $\begin{array}{c}\text { Amts. of agglomerated } \\
\text { particles }(\%)\end{array}$ & $<0.03$ \\
\hline
\end{tabular}

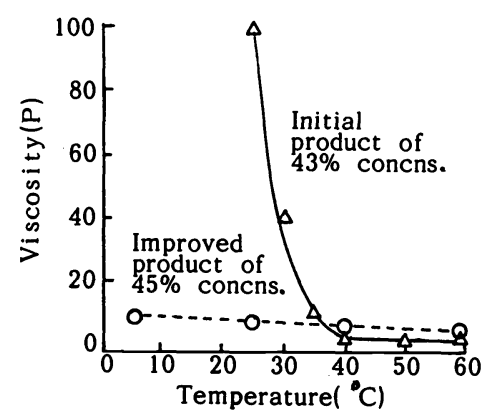

Fig. 8. Viscosities of zeolite slurries.

However, as the initially introduced zeolite slurry had relatively large temperature dependency in the viscosity, special lorries with a thermal insulation were needed for a long distance transportation to detergent plants. By modifying the dispersing agent system (ref. 9), the viscosity of the zeolite slurry was finally improved to one having low temperature dependency even in more concentrated state as shown in Fig. 8.

By this achievement the troubles in transportation and handling were solved. Table 3 shows a typical physical property of zeolite slurry developed for detergent use.

\section{PROPAGATION OF DETERGENT ZEOLITE}

The detergency in a soft water with 54ppm-hardness increases in relation to the amounts of zeolite formulated in the detergents, as shown in Fig. 9. In the combination with surfactants, the best result was obtained in the case with $\alpha$-olefin sulfonate (AOS) than the other cases with linear alkylbenzenesulfonate (LAS) or higher alcohol sulfate (AS). This could be explained by the basic properties of AOS that the calcium salt of AOS is more soluble and calciumand sodium complex salt of AOS has better surface activities than those of LAS or AS. Figure 10 shows the relation of detergency versus water hardness in each surfactant. Among them, AOS showed fairly good detergency up to considerably high water hardness regions.

It was also confirmed that the zeolite has a soil redeposition preventing effect in the presence of surfactants, and especially the effect is maintained even in relatively high water hardness regions in the case of AOS having an insensitive properties to the hardness. 
Considering these results, a prospect was obtained that it would be possible by selecting surfactants to formulate non-phosphated detergent having excellent cleaning effect essentially equal to conventional phosphated detergents.

In applying the obtained detergent formulation of the non-phosphated version with zeolite into the actual manufacturing processes, there were following difficulties: the drying rate of the sprayed detergent slurry is relatively low; the sprayed particles in wet state tend to agglomerate with each other in the spray dryer, yielding some large particles, and; the bulk density and physical properties of the spray-dried powder obtained are not suitable due to being heavier and stickier in comparison with conventional phosphated detergents.

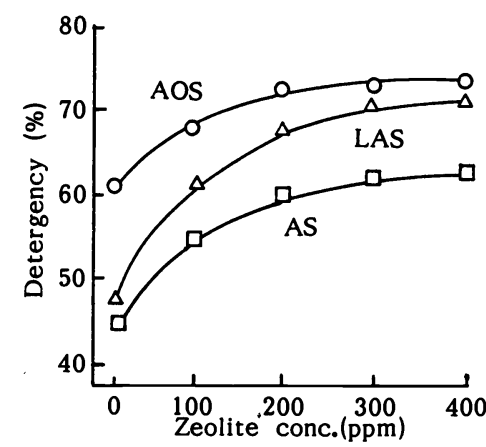

Conditions:

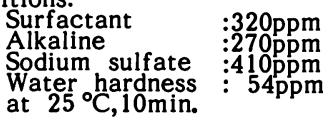

Fig. 9. Effect of Zeolite on detergency (ref. 10).

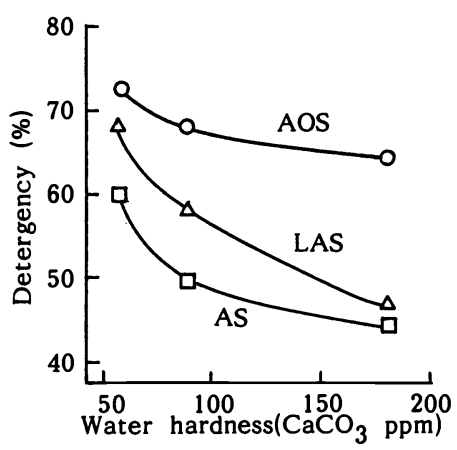

Conditions:

Surfactant $\quad: 320 \mathrm{ppm}$ Zeolite

Alkaline

Sodium sulfate
at $25^{\circ} \mathrm{C}, 10 \mathrm{~min}$

Fig.10. Effect of water hardness on detergency of various anionic surfactants (ref. 10).

By applying improved processes of multi-stage spray-drying and aeration of fine particle bubbles to the slurry (ref. 11, 12), the problems of productivity and heavy bulk density were almost resolved. The physical property of the powder detergent was also improved up to almost the same level of the phosphated detergent by applying dry-blending of small amounts of zeolite powder for the coating of the detergent-seed obtained by spray drying (ref. 13).

With these technical achievements, in the spring, 1980, the first completed non-phosphated powder detergent with high-level zeolite content was introduced initially in the specific areas which had serious eutrophication problems and then was expanded to national sales as the capability of supplying zeolite increased. This type detergents had not any inferior point comparing with the most popular phosphated detergents in performance properties as well as storage stabilities, differing from high-alkaline non-phosphated detergents with rather poor property, which had been introduced previously in the market a short time before the zeolitebased detergent. So the products have been favorably accepted by distributors and users, and up to now essentially no-claims have been reported about the qualities. Whereas the areas with phosphate bans represent only about $1.6 \%$ of Japanese population, today the shipment amounts of non-phosphated detergents occupy more than 95\% share in the total powder detergents. Contrary to this, the phosphated detergents amounts to less than $5 \%$ in the share and it is further expected that they will decrease much more or even disappear in near future.

In the detergent field, the total consumption amounts of zeolite were only 150 tons in 1976, and only powder-type zeolite was used as an anti-caking agent in dry blending process at that

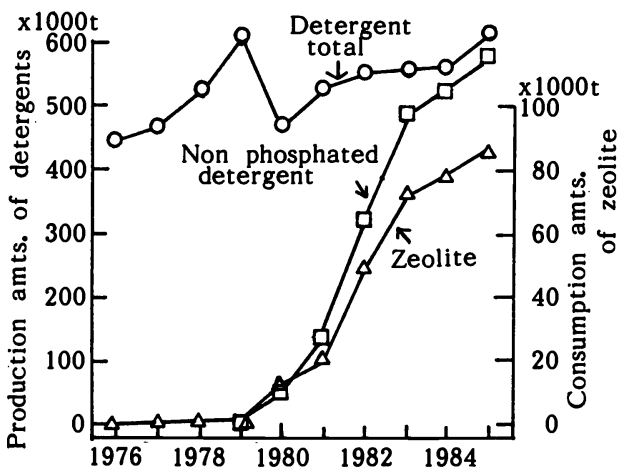

Fig.11. Production trends in synthetic powder detergents and detergent zeolite.

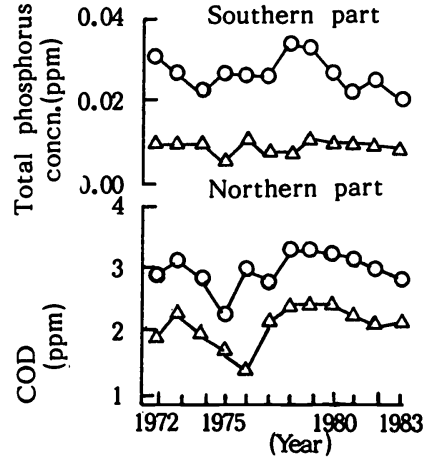

Fig. 12. Trend of water pollutions in Lake Biwa (ref. 14). 
time. Since the introduction of the completed non-phosphated detergent in 1980, the consumption amounts of detergent zeolites increased yearly and reached about 84,000 tons in 1985 (Fig. 11). The current composition of zeolites in this field is estimated as follows; slurry type $85 \%$, and powder type $15 \%$.

The another reason why zeolites have increased in the detergent field is due to the marketing of the non-phosphated detergents at the regular price, which was made possible with contributions by both parties through the achievement of technical tasks for the cost reduction of zeolite and the improvements in formulation and productivity of the detergents.

\section{FINAL COMMENTS}

The development of the non-phosphated detergents is one of the big technical revolutions in the history of synthetic detergents, which will be comparable with the switchover to soft-type detergents in the middle of $1960^{\prime} \mathrm{s}$. The zeolite developed for detergent use played a very important role in this revolution. In the facts that challenged the big technical tasks and worked to establish substantially non-phosphated detergent era by last year, the acid-clay process has made a big contribution as a pioneer to the development of detergent zeolites, especially to the commercialization of the specific zeolite having fine, small uniform-sized particles, which had not been obtained in the conventional zeolite process.

LION Corporation could market the zeolite-based non-phosphated detergent as a pioneer in Japan taking the most advantage of having an established technology on applying and manufacturing AOS, an excellent surfactant for the non-phosphate version. The basic pattern of the applied formulation has become a typical model for non-phosphated detergents currently marketed in the domestic market.

Regarding safety and sociological influence of zeolite, the data obtained by Henkel KGaA and other research institutes were very useful in applying zeolite as a phosphate substitute.

The signs of improvement in water pollution or eutrophication by the diffusion of the nonphosphated detergents have not been so clear up to now, but the results of survey conducted by Shiga Prefecture showed that the pollution and phosphorus concentration in Lake Biwa have shown an improvement trend (Fig. 12). This will be attributed to the switchover to the nonphosphated detergents as well as other related measures to reduce water pollution, conducted by the local governments. On the detergent zeolites discharged through household drainages into sewers, no significant influence has been reported in sewage systems and in sedimentation in surface waters. Under such circumstances, very active consumer union's movements against synthetic detergents have significantly decreased with the popularization of the non-phosphated detergents.

Thus in Japan having relatively low hardness water, the detergent phosphates could be substituted essentially by zeolite. While, in the USA and Europe with higher water-hardnesses, the switchover to lower-phosphated or non-phosphated detergents have been done by combinations of zeolite and chelating agents because of difficulties to formulate zeolite of more than about $20 \%$ due to troubles in spray-drying process caused in such concentrations of zeolite.

From view point of saving energy, the lower temperature washing would be more popular in the foreign countries which traditionally use hot or warm water in washing. So, in future the zeolites having smaller particle size will be accepted in these countries, too. We expect the developed technology on manufacturing and application of fine particle zeolite will spread in the world as a new knowledge or an example of scientific contribution to protecting environment.

\section{REFERENCES}

1. H.S. Reuss, 23rd Report by the Committee on Government Operations House Report No. 91-1004, April 14(1970).

2. S. Tomiyama and K. Ohba, Yukagaku, 20, 46 (1971).

3. M.M. Crutchfield, J. Am. Oil Chem. Soc., 55, 58 (1978).

4. H.S. Smolka and M.J. Schwuger, Colloid \& Polymer Sci., 256, 202 (1982).

5. T. Nakazawa, Yukagaku, 32, 202 (1982).

6. G.S. Schweiker, J. Am. Oil Chem. Soc., 55, 36 (1978).

7. R.E. Grim, "Clay Mineralogy", p.56, McGraw-Hill Book Co.(1953).

8. Not published. A part of the results will be given by M. Ogawa, T. Nakazawa and K. Abe, Mizusawa Industrial Chemicals Ltd. at the poster session in 7 th International Zeolite Conference.

9. Examined Japanese Patent Application 60-49127, Laid Open Japanese Patent 58-172222.

10. H. Nishio, M. Mukaiyama and O. Okumura, 14th Symposium on Detergency, Japan Oil Chem. Soc., Kohbe, Oct. (1983).

11. Laid Open Japanese Patent Application 57-192499.

12. M. Nakamura and S. Toyoda, 4th International Drying Symposium, p.403 (1984).

13. Examined Japanese Patent Application 59-21360.

14. The White Paper on Environments (Shiga Prefecture), (1983). 